\title{
A participatory approach for modeling alternative future land use scenarios around Nairobi National Park using Bayesian Belief Networks
}

\author{
J. T. McCloskey ${ }^{1}$, R. J. Lilieholm ${ }^{1}$, R. Boone ${ }^{2}$, R. Reid ${ }^{2}$, \\ S. Sader ${ }^{1}$, D. Nkedianye ${ }^{3}$, M. Said ${ }^{3} \&$ J. Worden ${ }^{4}$ \\ ${ }^{1}$ School of Forest Resources, University of Maine, USA \\ ${ }^{2}$ Warner College of Natural Resources, Colorado State University, USA \\ ${ }^{3}$ International Livestock Research Institute, Nairobi, Kenya \\ ${ }^{4}$ African Conservation Fund, Nairobi, Kenya
}

\begin{abstract}
We develop an adaptive and flexible framework for engaging experts and stakeholders at the household- and community-level that have different livelihoods and land use interests within Kenya's Athi-Kaputiei Plains (AKP). We use Bayesian Belief Networks linked to GIS data layers to integrate empirical data and elicited stakeholder knowledge. The process is designed to address problems with past conservation-development strategies by allowing participants to build relationships among people with different land use interests in order to clarify opportunities and constraints, examine assumptions at the design phase of a project, and determine future actions and potential development scenarios. We use an example of four different livelihood groups in the AKP to demonstrate how the process might work to identify suitable areas for alternative land uses (e.g., wildebeest and livestock grazing, crop cultivation, and urban development), and to identify future compatibilities and conflicts between these different land use interests. The modeling process provides a maximal coverage strategy that allows decision makers to target and prioritize areas for protection or development, and to set specific strategies in the face of changing ecological, social, or economic processes. The process is iterative so that revised models can be developed as new data and knowledge arise, thereby
\end{abstract}


helping communities and other interests learn from past successes and failures, and better evaluate the impacts of alternative land uses.

Keywords: Bayesian Belief Networks, collaborative management, communitybased conservation, integrated conservation and development projects (ICDPs), landscape change, land use, livelihoods, Nairobi National Park, participatory modeling, pastoralism, wildlife.

\section{Introduction}

The challenges and limitations facing conservation strategies such as integrated conservation and development projects (ICDPs), community-based conservation (CBC), and traditional protected areas like national parks are well documented in the literature [1-4]. These include the need for thematic coherence at the design phase, an understanding of community heterogeneity and complexity, including local communities in all phases of a project, mechanisms for monitoring and evaluation with respect to project goals and objectives, collaboration with other relevant projects, and the adoption of adaptive and flexible management approaches $[1,4]$.

Here, we address the shortfalls learned from past conservation and development strategies by developing a participatory framework that demonstrates how a diverse set of stakeholders with different land use interests can be engaged to identify suitable areas for wildlife migration, livestock grazing, crop cultivation, and urban development in the Athi-Kaputiei Plains (AKP) - the region south of Kenya's Nairobi National Park (NNP). The method uses Bayesian Belief Networks (BBN) linked to spatial data in order to identify suitable areas for alternative land uses, and to identify future compatibilities and conflicts. The result is a stakeholder-driven land use planning and analysis tool that provides decision makers with multiple options for targeting and prioritizing areas for conservation protection and economic development.

\section{Background}

Sustainability science recognizes the need to integrate social, economic and ecological information. Adaptive management is the continuous integration of design, management and monitoring to systematically test assumptions in order to adapt and learn [5]. The ultimate goal is to design resilient institutions that have the flexibility to modify policy in response to changing ecological and socio-economic environments. To build truly adaptive institutions, however, scientists, stakeholders and planners must collaboratively interpret and integrate scientific knowledge, evaluate the outcomes of management decisions, and revise and improve future management policies and actions [6]. The proximate goal, then, is to identify the relationships between scientific research, past experience, and public policy, thereby forging a mechanism for effective policy change (e.g., [7-9]).

Sociologists suggest that for meaningful policy change to occur, three aspects of the social structure must interlock and reinforce each other: (1) the allocation 
of resources and power that governs our ability to take effective action; (2) the myths, paradigms, or ideologies that frame our activities; and (3) the rules and norms that organize human actions [10]. These factors affect not only the ability of an institution (or individual) to detect and understand new scientific knowledge, but also its capacity to alter its worldview, which is implicit for successful knowledge integration and adaptive management.

First, the allocation of resources and power (or lack thereof) is often cited as a primary factor limiting the success of conservation efforts such as ICDPs, CBC projects, and national parks and reserves [1-4]. Indeed, few conservation strategies succeed without long-term financial support and effective laws, policies and regulations [2]. Meeting these requirements necessitates the integration of factors across multiple scales - from international and national policy advocacy, to site-based participation from local stakeholders. Wells et al. [11] review lessons learned from past ICDPs and offer advice for financial sustainability. Here, an important first-step is the creation of a participatory process that brings together diverse interests during the conceptual phase of a project to ensure that local- and national-level policies and conservationdevelopment linkages are better understood and represented $[3,12]$.

The second factor cited above - the myths, paradigms, or ideologies that frame human activities - has also been identified as a weakness of many conservation strategies [1-4]. Indeed, ICDPs and CBCs have emerged over the last few decades in response to the recognition that humans and protected areas must successfully coexist in order to ensure the long-term viability of conservation efforts. These models emerged in reaction to the "guns and fences" approach that dominated conservation strategies until the 1990s, and which toooften failed to account for the interactions and complexities of coupled socioecological systems (SES) [13-15].

While effectively operating within such complexity requires greater effort in planning and decision-making, if individuals working together share a common world-view (i.e., paradigm), complex decisions can be easier to address [10]. However, the stronger a paradigm, the less receptive an institution will likely be to new knowledge [10]. Thus, any successful conservation-development strategy will need to have adaptable and flexible institutions and decision-making processes. Furthermore, complicated ecological modeling methods may actually add to the uncertainty of scientific knowledge, thereby complicating the decision-making process for practitioners and laypeople $[9,16]$. We agree with Salafsky and Margoluis [5], who suggest that adaptive management does not necessarily need complicated methods, but instead should concentrate on designing conceptual models of relationships capable of testing assumptions, monitoring natural and human SES features, and systematically testing alternative actions. Any adaptive process should also encourage participation and learning by a diverse set of institutions, organizations, stakeholders, and individuals.

Finally, the rules and norms that organize our activities - together with power structures and paradigms (i.e., the other two aspects of the social structure) combine to shape our basic assumptions of the world. A synthesis of ICDP and 
CBC case studies suggests that weak assumptions, not identified until long-after implementation, have constrained the success of many projects $[2,11,12]$. These same studies show, however, that many false assumptions could have been discovered at the design phase of the project through in-depth discussion with a diverse set of participants $[2,11,12]$. Case study evaluations have consistently called for improved collaborative decision-making between planners and communities $[1,3,4,12,17,18]$.

We use this view of social structure and its links to policy change as the foundation for a participatory process designed to accommodate the knowledge, values, and opinions of a diverse set of decision makers, scientists, and stakeholders. We feel that this suite of interests, often excluded from protection strategies in the past, provides the key to strengthening the sustainability of future conservation and development efforts.

\section{Study area}

Kenya's AKP cover over 2,590 $\mathrm{km}^{2}$ of rolling plains that once supported the migration of wildlife populations second in size to only the Mara-Serengeti region [19], fig. 1. Nairobi National Park covers a small portion of the northern AKP system, but serves as a crucial reserve for wildlife during the dry seasons. The Park is fenced on three sides and bordered to the north by Nairobi - one of the largest and fastest-growing cities in Africa [20].

Nairobi's population has increased from 500,000 people in 1970 to over 3 million people today [20]. This growth has been characterized by residential and commercial expansion and intensified land use. With limited land use planning, growth has outpaced infrastructure and human services to create large slums and unplanned settlements in peripheral areas, fig. 2. Lack of planning, combined with physical constraints and mounting environmental impacts, threaten the sustainability of both human and natural systems, fig. 2 . These include the viability of urban centers, Maasai pastoral livelihoods, and broader landscape processes such as globally significant wildlife migration patterns [20].

\section{Socio-ecological (SES) setting: identifying participants}

Nkedianye et al. [21] have shown four distinct livelihood strategies in the AKP diversified agro-pastoralists, pastoralists with wildlife income, marginal pastoralists, and wage-earning agro-pastoralists. Pastoralism remains the most important source of income for many in the AKP. Nevertheless, wildlife-based tourism is still viewed as the basis for sustainable development across many of East Africa's rangelands [22]. The Maasailands of Kenya and Tanzania alone generate an estimated $\$ 1.5$ billion in tourism revenues each year [22]. Past policies and many development projects are based on the assumption that community-based or private conservation initiatives will help reduce poverty while maintaining wildlife populations. In reality, the benefits from such initiatives are often limited, and there is gathering evidence that these assumptions are unrealistic - both in terms of increasing wildlife populations and 


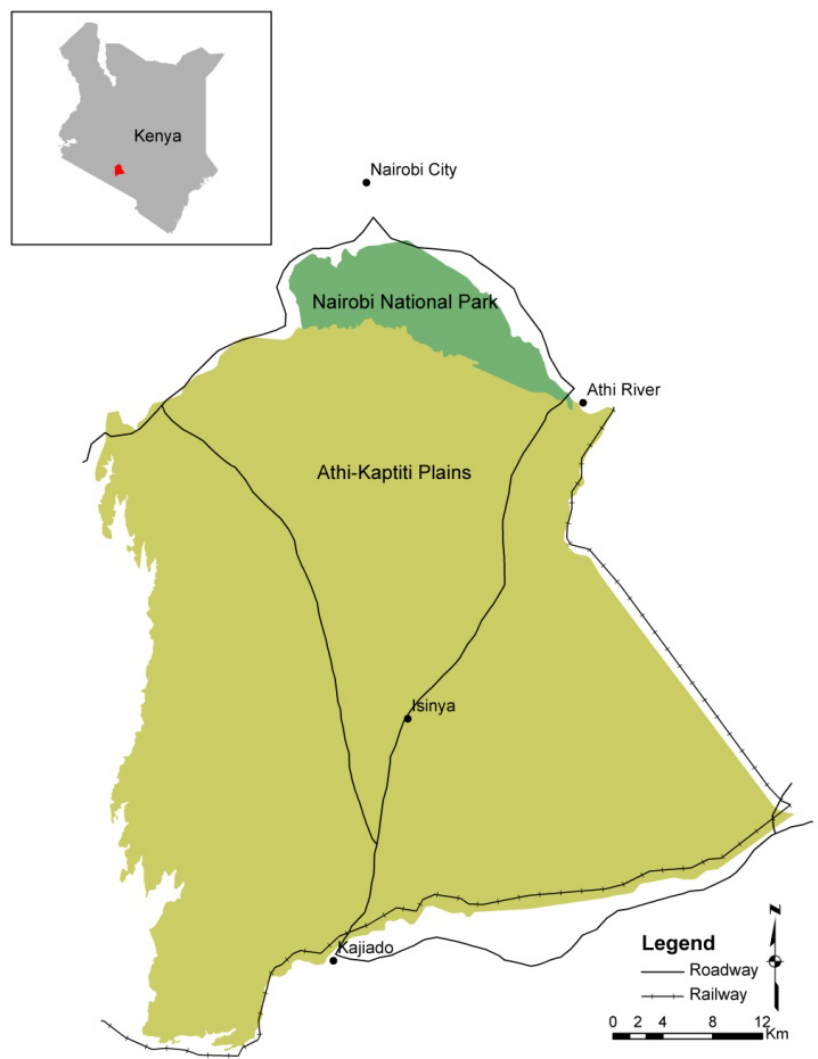

Figure 1: $\quad$ Nairobi National Park and the Athi-Kaputiei Plains of Kenya.

reducing poverty [22-25]. In fact, most wildlife populations across Kenya have declined considerably over the last 30 years despite the work of numerous governments, non-government organizations (NGOs), entrepreneurial initiatives, and scientific research efforts [26, 27].

In terms of poverty reduction, Homewood et al. [22] demonstrate that across Maasailand, wildlife earnings are poorly distributed among local communities and contribute little earnings when compared to households that rely on livestock, farming, and/or non-farm wage work. In the rare communities where wildlife revenues do generate a significant proportion of income, it is primarily distributed to households who own land near high-visitation conservation areas. Furthermore, households earning the most from wildlife often invest in land use practices (e.g., cultivation) that may undermine wildlife or pastoral livelihoods [22]. This is consistent with other studies that dispute the widespread assumption that by providing alternative income opportunities, ICDPs can reduce the use of natural resources by local people $[1,17]$. 

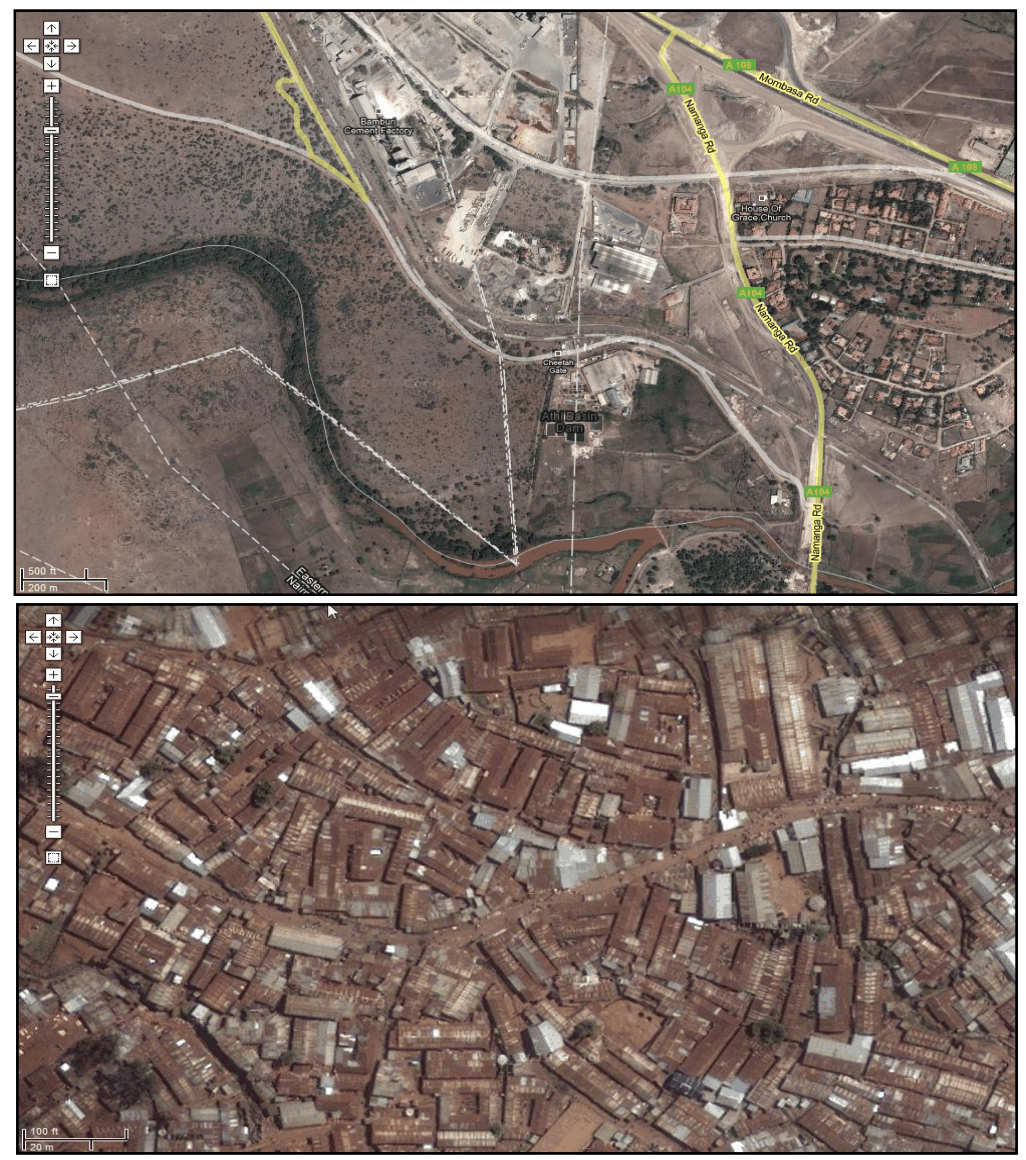

Figure 2: A cement plant in the north-central portion of the top photo borders the eastern edge of Nairobi National Park, shown to the west. The town of Athi-River lies to the east. Such towns develop around industrial areas and transport corridors as a result of ad-hoc land use planning. The bottom photo shows Nairobi's Kibera slums, a densely-settled area located just $3 \mathrm{~km}$ north of Nairobi National Park (courtesy of Google Earth).

Homewood et al. [22] offer three explanations for the apparent gap between the expectations and assumptions of policies and decisions based on conservation theory and the reality for individual households and wildlife populations across Maasailand. These include: (1) how ecotourism revenues are distributed; (2) how pastoral production systems are perceived and valued by different people and institutions; and (3) how project impacts are measured. These considerations are essentially the same as those of any social structure identified above by Westley [10] as crucial for linking knowledge to meaningful 
changes in policy (i.e., the allocation of power and resources, paradigms/worldviews, and rules and norms). The first step, then, is to identify participants from the community and household-level who can represent the four livelihood strategies identified by Nkedianye et al. [21], as well as decision makers and experts who understand the policies, regulations, and institutional arrangements of the area (e.g., planners, developers, conservationists, agricultural interests, and scientists), fig. 3.

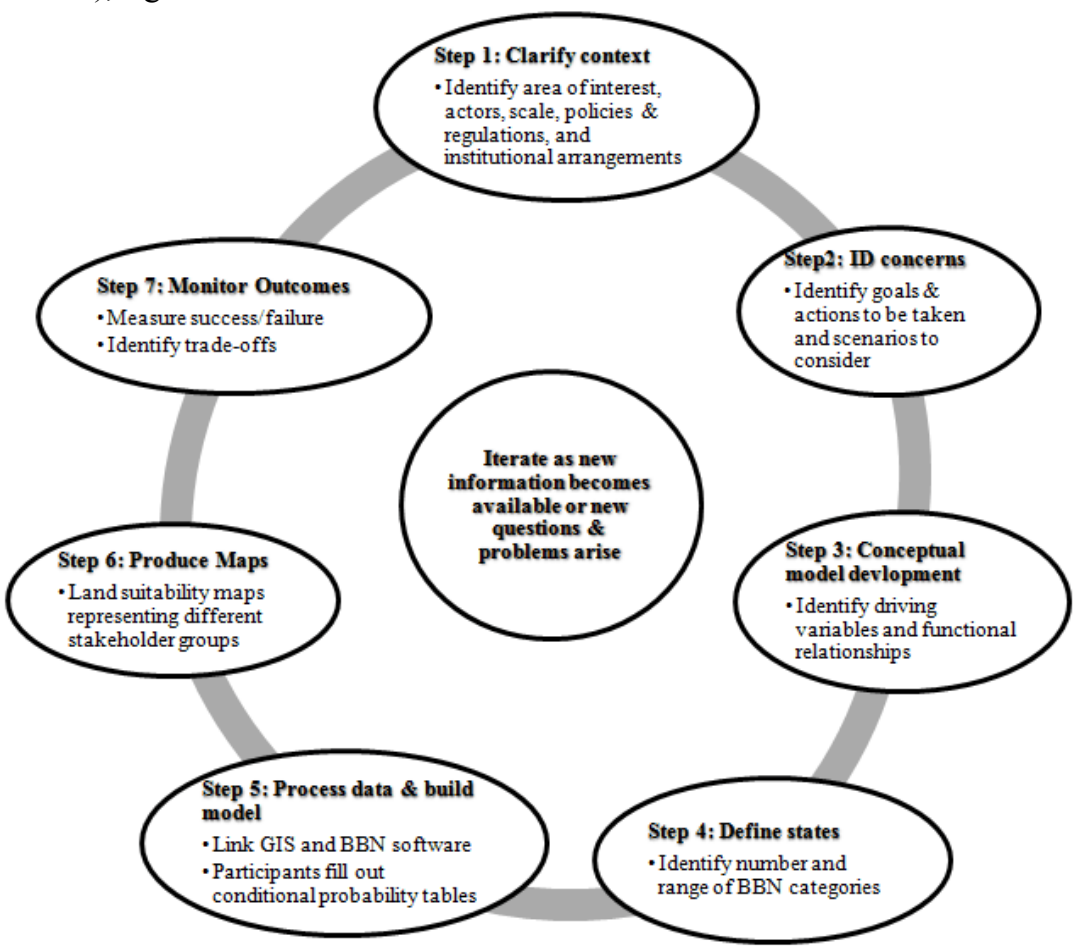

Figure 3: A framework for a participatory process to identify the suitability and potential conflict of different land uses.

\section{Translating SES setting into spatial variables}

A number of historic and geopolitical events have marginalized or excluded some interests and benefited others in the AKP region, thus contributing to the structural poverty of the area [22, 28]. In addition, impacts from biophysical events (e.g., drought) and the loss of mobility and access due to changes in land use (i.e., gazetting of protected areas, urbanization, and large-scale cultivation) have contributed to conjunctural poverty $[22,28]$. Alleviating these two types of poverty requires different and complex strategies and tactics over various scales. In either case, those that have been well-positioned during past events (e.g., adjacent to wildlife reserves or perennial water sources) have an advantage over those less-well placed [22]. Indeed, like everywhere, different stakeholders in the 
AKP have different types of power and resources. Consequently, they have different world views, understandings of local processes, and political and economic interests and influences [22]. These differences in the social structure among AKP participants influence the identification, threshold settings, and ranking of variables deemed important in any participatory modeling process.

\subsection{Stakeholder modeling workshops}

Using this knowledge, we designed a process similar to W.E. Deming's continual improvement model [29] that includes four separate workshops - one for each livelihood strategy - to begin to engage household and community-level participants and build relationships, fig. 3. During the workshops, participants first clarify the freedoms and constraints (e.g., policies and regulations) in order to identify the range of possibilities. Next, the actions that are needed and scenarios that might arise are considered. These first two steps begin to identify real and perceived assumptions. Next, we identify important environmental and economic variables that can be spatially associated with the suitability of land for wildebeest and livestock grazing, crop cultivation, and urban development. The variables are identified by conducting a review of the current literature, engaging community and household-level stakeholders in workshops and focus groups, and holding multiple meetings with scientists and planners with expertise in ecology, economics, cultural anthropology, and agriculture. During the workshops, participants identify important biophysical metrics to be used as spatial variables intended to identify areas that stakeholders deem to be suitable for wildebeest, livestock, crop cultivation, and urban development. These stakeholder- and expert-defined metrics are then used to create BBNs describing the functional relationships between variables. Participants then rank the importance of the a priori spatial conditions identified by the empirical data. If there is debate over the inclusion or exclusion of variables or definitions, differences can be explored to determine consistency of outcomes or to allow explicit weighting of alternative views. During the workshops, scenarios are identified for further analysis of alternative futures for wildebeest, livestock, and crop cultivation, in order to assess the likely consequences and tradeoffs between conserving these areas and allowing urban development.

Prior to the workshops, we use the expertise of scientists to identify potential variables used to develop "pilot" BBN influence diagrams for each land use, fig. 4. The first box (i.e., land availability) in each diagram acts as a filter that, under an idealized scenario, provides a considerable amount of land for development while protecting important areas (e.g., wetlands). The amount of land potentially available for each use will be determined from a land cover map based on high-resolution SPOT data acquired in October 2010. For example, the development diagram in fig. 4 contains six GIS and remotely sensed data layers (variables) thought to influence commercial and residential development in the AKP. The initial land cover map is then re-coded to represent the two states available and unavailable for future development in the AKP. Because we are interested in future development, we assume existing urban areas to be unavailable. Likewise, because we are interested in finding common ground 
A) Suitability for Development

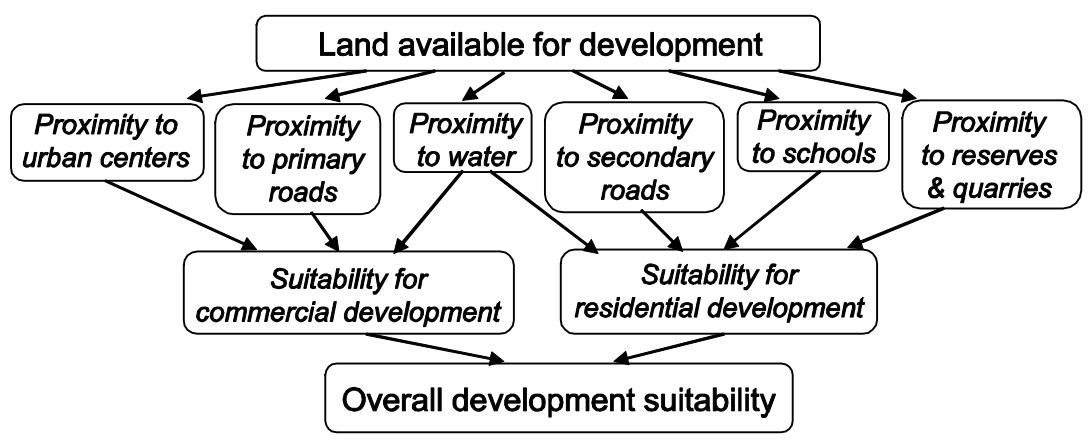

B) Suitability for Crop Cultivation

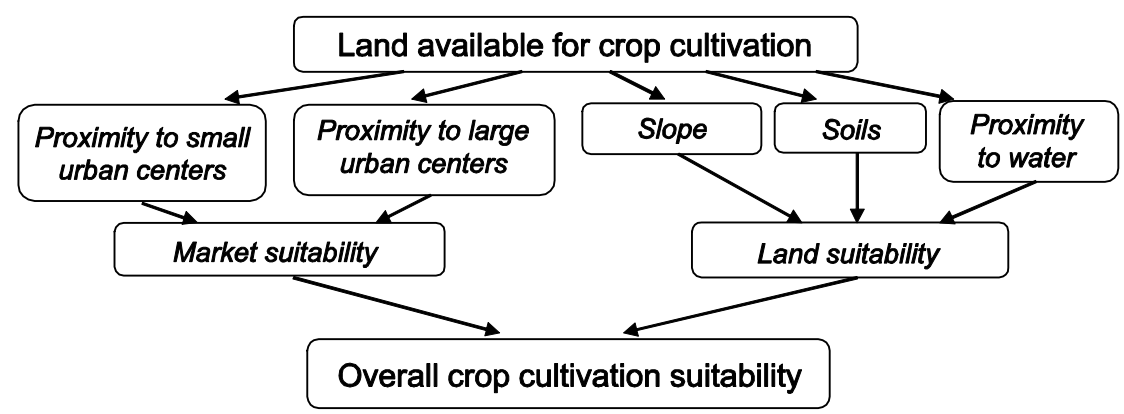

C) Suitability for Wildebeest \& Livestock

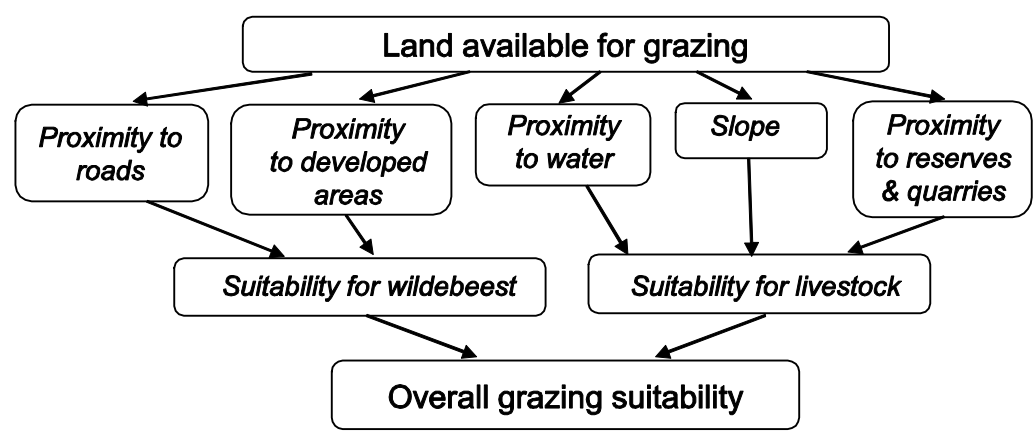

Figure 4: Influence diagrams showing key factors affecting development (A), crop cultivation (B), and wildlife and livestock grazing (C) in the AKP. 
between development and conservation interests, riparian areas are assumed unavailable for development. Areas already classified as current conservation lands are also assumed to be unavailable for development.

The crop cultivation diagram, fig. 4B, contains five variables thought to influence the market and land suitability for certain crops in the AKP. The initial land cover map will be re-coded differently than above in order to represent the two states (i.e., available and unavailable) for all potential future crop cultivation lands in the AKP. Unavailable land includes urban areas, roads, water, current conservation lands, quarries, nurseries, and woodlands. All other land cover types are considered available as potential future crop land.

Finally, the wildlife and livestock diagram, fig. 4C, includes five variables thought to affect the suitability for wildebeest and livestock grazing in the AKP. Again the initial land cover map will be re-coded to represent the two states (i.e., available and unavailable) for all potential future grazing lands in the AKP. Unavailable land includes urban areas, roads, quarries, nurseries, and current crop lands. All other land types are considered available as grazing land.

The nodes and links of the influence diagrams in fig. 4 will eventually be developed into BBNs that represent functional relationships among variables [30]. Each node will have two-to-four user-defined states with a probability table that expresses the probability of each state either as prior distributions or as conditional on the probability of each state for the source nodes [30]. The prior probability tables are derived from empirical spatial data, whereas the conditional probability tables (CPT) are entered manually based on stakeholder and expert opinion elicited during the workshops [31].

The output from the above process will be four suitability maps for each of the four land uses. These four maps are then over-layed with each other to identify areas of potential conflict and compatibility [32]. A final workshop brings together the four groups of stakeholders in order to get an understanding of how the different land uses complement and conflict under various future development scenarios.

\section{Advantages of using Bayesian Belief Networks}

As simplifications of reality, all models have strengths and weaknesses, and none provide a panacea for understanding and managing complex natural and human systems [33]. This is true whether they be BBN models, expert system models, agent-based models, or neural networks. When it comes to BBNs, they can be limited by the quality and extent of prior beliefs or conditions, their inability to deal with unusual or unanticipated events, and the computational difficulty of exploring previously unknown networks [33].

In this case study, the first limitation is addressed by specifying the prior probability tables from case files of empirical spatial data [31, 32, 34]. In addition, the use of expert knowledge and diverse stakeholder groups to identify the appropriate variables, their structural and functional relationships, and explore alternative scenarios, allows us to consider unanticipated events and explore different network structures - features that we consider to be strengths, 
not weaknesses. For example, identifying suitable areas for wildlife, livestock, crop cultivation, and urban development will provide multiple potential locations for future development projects that do not interfere with the needs of pastoral people and ecotourism use and development. However, there are factors not considered in the current suitability models (e.g., ownership and land value). Thus, higher resolution spatial data will likely be needed for specific, smallerscale (i.e., parcel-level) planning. This will require new BBN models, informed by the existing modeling framework, to allow planners and stakeholders to continue to build relationships and learn from past experience. Thus, we agree with others who have documented the advantages of BBNs over traditional modeling efforts and believe the advantages of BBNs outweigh potential limitations [14, 15, 33].

Another advantage of BBNs and the framework presented here is that we recognize the uncertainty of scientific knowledge [33]. Our own experience with BBNs [32] as well as others' [34], suggest that they are easy to calibrate, validate, and update as new information becomes available. Thus, BBNs fit well with the concepts of adaptive management [35] and can be a useful tool for organizing current thinking, generating testable hypotheses, comparing alternatives, and incorporating the uncertainty of scientific data. However, their use must be guided by observation, inference, and careful thinking, thereby underscoring the need for multiple working hypotheses [36].

\section{Conclusions}

The participatory modeling process proposed here provides an appropriate experimental design that can be implemented to link stakeholder and expert knowledge to actual policy change and land use planning decisions [16]. Bringing a diverse set of individuals together provides the capacity to build relationships, monitor responses, evaluate effectiveness, and consider economic opportunity and social equity for otherwise marginalized people, which we see as the keystone to sustaining natural and human systems [16, 37].

The community- and household-level stakeholder-led framework developed here directly links SES components. The process allows planners and stakeholders to learn how to use spatial and non-spatial data to explore realworld problems and scenarios, and identify areas suitable for development needs and various livelihood strategies (e.g., livestock, cropping, and wildlife uses). We acknowledge that there are no "one-size-fits all" solutions, and that no single modeling approach will be a panacea for natural resource and sustainability issues in Maasailand or anywhere else. Instead, the process described here encourages input from local people who rely on the AKP system for their livelihood and cultural identity in order to identify the impacts that are most important to them. Thus, we offer methods that can be easily understood and measured by local decision makers and stakeholders.

Finally, this process can be easily adapted as new information becomes available, or as new problems arise. The current model structure provides a maximal coverage strategy that allows diverse land use interests to be brought 
together to target and prioritize areas for protection or development, and to set specific strategies in the face of changing ecological, social, and economic processes [32]. Having multiple options can generate new hypotheses and decisions at the local scale, and may provide insight into solving more specific conservation needs not yet identified by stakeholders and decision makers. Subsequently, new models can be developed using the same process, but with higher-resolution data, thereby helping communities and other interests evaluate the impacts of alternative land uses between different prioritized areas at finer scales. As a result, future land use decisions can be made using the most up-todate SES information [16].

Diverse and non-traditional stakeholder involvement ensures transparency and defensibility and should increase stakeholder capacity to develop, understand and react to alternative futures. By using this process to engage stakeholders, we expect to foster increased collaboration, expanded social capital, and better-targeted development and conservation proposals. To the extent that these outcomes are realized, we would expect to gain incremental improvements in quality-of-place, and more sustainable rural and urban economies across the AKP region.

\section{Acknowledgements}

This project was supported by NSF awards DEB-0919383 and EPS-0904155. Additional support was provided by the Maine Agricultural and Forest Experiment Station, and the Center for Research on Sustainable Forests.

\section{References}

[1] Browder, J.O., Conservation and development projects in the Brazilian Amazon: Lessons from the community initiative program in Rondonia. Environmental Management, 29(6), pp. 750-762, 2002.

[2] McShane, T.O. \& Newby, S.A. Expecting the unattainable: The assumptions behind ICDPs (Chapter 4). Getting Biodiversity Projects to Work: Towards More Effective Conservation and Development, eds T.O. McShane \& M.P. Wells, Columbia University Press: New York, pp. 49-74, 2004.

[3] Linkie, M., Smith, R., Zhu, Y., Martyr, D., Suedmeyer, B., Pramono, J. \& Leader-Williams, N., Evaluating biodiversity conservation around a large Sumatran protected area. Conservation Biology, 22(3), pp. 683-690, 2008.

[4] Blom, B., Sunderland, T. \& Murdiyarso, D., Getting REDD to work locally: Lessons learned from integrated conservation and development projects. Environmental Science \& Policy, 13, pp. 164-172, 2010.

[5] Salafsky, N. \& Margoluis, R. Using adaptive management to improve ICDPs (Chapter 16). Getting Biodiversity Projects to Work: Towards More Effective Conservation and Development, eds T.O. McShane \& M.P. Wells, Columbia University Press: New York, pp. 372-394, 2004. 
[6] Gunderson, L.H., Holling, C.S. \& Light, S.S., (eds). Barriers and Bridges to the Renewal of Ecosystems and Institutions, Columbia University Press, New York, 1995.

[7] Song, S.J. \& M'Gonigle, M., Science, power, and system dynamics: The political economy of conservation biology. Conservation Biology, 15, pp. 980-989, 2001.

[8] Endter-Wada, J., Blahna, D., Krannich, R. \& Brunson, M., A framework for understanding social science contributions to ecosystem management. Ecological Applications, 8, pp. 891-904, 1998.

[9] Finlayson, A.C., Fishing for Truth: A Sociological Analysis of Northern Cod Stock Assessments From 1977-1990, Institute of Social and Economic Research, Memorial University of Newfoundland, St. John's, Newfoundland, Canada, 1994.

[10] Westley, F.R., Governing design: The management of social systems and ecosystem management. Barriers and Bridges to Renewal of Ecosystems and Institutions, eds. L. Gunderson, C.S. Holling, \& S. Light, Columbia University Press, New York, pp. 391-427, 1995.

[11] Wells, M.P., McShane, T.O., Dublin, H.T., O’Connor, S. \& Redford, K.H., The future of integrated conservation and development projects: Building on what works. Getting Biodiversity Projects to Work: Towards More Effective Conservation and Development, eds T.O. McShane \& M.P. Wells, Columbia University Press: New York, pp. 397-421, 2004.

[12] Mistry, J., Berardi, A., Simpson, M., Davis, O. \& Haynes, L., Using a systems viability approach to evaluate integrated conservation and development projects: Assessing the impact of the North Rupununi adaptive management process, Guyana. The Geographical Journal, 176(3), pp. 241-252, 2010.

[13] Anderson, D.R., Burnham, K.P. \& Thompson, W.L., Null hypothesis testing: Problems, prevalence, and an alternative. Journal of Wildlife Management, 64, pp. 912-923, 2000.

[14] Clarke, J.S. \& Gelfand, A.E., A future for models and data in environmental science. Trends in Ecology and Evolution, 21, pp. 375-380, 2006.

[15] Grunkemeier, G.L. \& Payne, N., Bayesian analysis: A new statistical paradigm for new technology. The Society of Thoracic Surgeons, 74, pp. 1901-1908, 2002.

[16] Pullin, A.S., Knight, T.M., Stone, D.A. \& Charman, K., Do conservation managers use scientific evidence to support their decision-making? Biological Conservation 119, pp. 245-252, 2004.

[17] Herrold-Menzies, M., Integrating conservation and development: What we can learn from Caohai, China. The Journal of Environment \& Development, 15(4), pp. 382-406, 2006.

[18] Rinzen, C., Vermeulen, W.J.V., Wassen, M.J. \& Glasbergen, P., Nature conservation and human well-being in Bhutan: An assessment of local community perceptions. The Journal of Environment \& Development, 18(2), pp. 177-202, 2009. 
[19] Gichohi, H., Gakahu, C. \& Mwangi, E., Savannah ecosystems. East African Ecosystems and their Conservation, eds. T.R. McClanahan \& T.P. Young, Oxford University Press: Oxford, UK, pp. 191-207, 1996.

[20] Mundia, C. \& Aniya, M., Analysis of land use/cover changes and urban expansion of Nairobi city using remote sensing and GIS. International Journal of Remote Sensing, 26, pp. 2831-2849, 2005.

[21] Nkedianye, D., Radeny, M., Kristjanson, P. \& Herrero, M., Assessing returns to land and changing livelihood strategies in Kitengela. Staying Maasia?, eds. K. Homewood, P. Kristjanson \& P.C. Trench, Springer: New York, pp. 115-149, 2009.

[22] Homewood, K., Kristjanson, P. \& Trench, P.C., Changing land use, livelihoods, and wildlife conservation in Maasailand. Staying Maasia?, eds. K. Homewood, P. Kristjanson \& P.C. Trench, Springer: New York, pp. 142, 2009.

[23] Murombedzi, J., Devolution and stewardship in Zimbabwe's CAMPFIRE program? Journal of International Development, 11(2), pp. 287-293, 1999.

[24] Anderson, D. \& Berglund, E., Ethnographies of Conservation: Environmentalism and the Distribution of Privilege, Berghahn Books, New York, 2003.

[25] Mapedza, E. \& Bond, I., Political deadlock and devolved wildlife management in Zimbabwe. The Journal of Environment \& Development, 15(4), pp. 407-427, 2006.

[26] Ottichilo, W.K., de Leeuw, J., Skidmore, A.K., Prins, H.H.T. \& Said, M.Y., Population trends of large non-migratory wild herbivores and livestock in the Maasai Mara ecosystem, Kenya, between 1977 and 1997. African Journal of Ecology, 38, pp. 202-216, 2001.

[27] Homewood, K., Trench, P.C. \& Kristjanson, P., Staying Maasai? Pastoral livelihoods, diversification and the role of wildlife in development. Staying Maasia?, eds. K. Homewood, P. Kristjanson \& P.C. Trench, Springer: New York, pp. 369-408, 2009.

[28] Galaty, J. \& Bonte, J., Herders, Warriors and Traders. Pastoralism in Africa, Westview Press: Boulder, CO, 1991.

[29] Heizer, J. \& Render, B., Operations Management, $6^{\text {th }}$ ed. Prentice Hall, New Jersey, 2001.

[30] Steventon, J.D., Sutherland, G. \& Arcese, P., A population-viability-based risk assessment of Marbled Murrelet nesting habitat policy in British Columbia. Canadian Journal of Forest Research, 36, pp. 3075-3086, 2006.

[31] Marcot, B., Steventon, J., Sutherland, G. \& McCann, R., Guidelines for developing and updating Bayesian belief networks applied to ecological modeling and conservation. Canadian Journal of Forest Research, 36, pp. 3063-3074, 2006.

[32] McCloskey, J.T., Lilieholm, R.J. \& Cronan, C.S., Using Bayesian Belief Networks to identify potential compatibilities and conflicts between development and landscape conservation. Landscape and Urban Planning, in press, 2010. 
[33] Pourret, O., Naim, P. \& Marcot, B., Bayesian Networks: A Practical Guide to Applications, John Wiley \& Sons, Ltd: West Sussex, England, 2008.

[34] Smith, C., Howes, A., Price, B. \& McAlpine, C., Using a Bayesian belief network to predict suitable habitat of an endangered mammal - The Julia Creek dunnart (Sminthopsis douglasi). Biological Conservation, 139, pp. 333-347, 2007.

[35] Prato, T., Bayesian adaptive management of ecosystems. Ecological Modeling, 183, pp. 147-156, 2005.

[36] Chamberlain, T. C., The method of multiple working hypotheses. Journal of Geology, 5, pp. 837-848, 1987. Reprinted in Science 148, pp. 754-759, 1965.

[37] Leonard, H.J., Environment and the Poor: Development Strategies for a Common Agenda, Transaction Books, New Brunswick, New Jersey, 1989. 